\title{
Generating multi-component multi-layer coatings type mecraly using multi-cathode magnetron sputtering systems
}

\author{
Valery Kolesnik ${ }^{1}$, Yury Rubanov ${ }^{1}$, and Yulia Tokach ${ }^{1, *}$ \\ ${ }^{1}$ BSTU after V. G. Shukhov, Kostyukov str., 46, Belgorod, 308012, Russia
}

\begin{abstract}
The paper presents the results of experiments carried out to obtain multi-component coatings that have a broader range of properties compared to their single-component counterparts. We have studied the generation of coatings based on a $\mathrm{Co}(18 \ldots 20 \%)-\mathrm{Cr}(5 \ldots 7 \%)-\mathrm{Al}(0.3 \ldots 0.4 \%)-\mathrm{Y}(0.2 \ldots 0.5)$ alloy. We have also studied the chemical composition of the coating, its thickness, and the transient zone condition. We present here the results of X-ray fluorescence and X-ray spectroscopy microanalysis of such coatings. It is shown that the microtopography of surfaces depends on the coating generation conditions; the set of chemical elements in each coating is similar for all specimen, their concentration depends on the deposition conditions, and the thickness distribution is constant; there is virtually no diffusion of coating and substrate materials. We have identified an insignificant percentage of substrate materials in the generated coating. The thicker the coating, the less substrate materials it contains.
\end{abstract}

\section{Introduction}

Scientific and technical literature contains a lot of information on how to generate multi-component coatings with specified characteristics and adjustable composition [1-9]. Such coatings are widely applied in air, rocket, and mechanical engineering. One of the main causes of gasturbine engine compressor failure is the dust erosion of blade airfoils, which is particularly evident when aircraft and helicopters are operated at ground airfields or are flown low in excessively dusty air. On the other hand, improving the efficiency of ground and air turbines necessitates higher temperatures of input gases, which creates excessive temperature loads on the 'hot tract' parts, particularly on the blades. This is why the service life of engines directly depends on the service life of blades.

One of the ways to prolong the service life of engines it to protect compressor and turbine blades from erosive and thermal effects by applying protective coatings [1014].

Vacuum sputtering is used to create quality precision coating. Widely used coating materials are MeCrAlY where the main component (Me) is cobalt, cobalt plus nickel, cobalt plus chromium, etc.

\section{Methodology}

To study how multi-layer coatings based on multicomponent alloys can be generated, we experimentally sputtered a Co (18...20\%)-Cr (5...7\%)-Al (0.3 ..0.4\%)$\mathrm{Y}(0.2 \ldots 0.5)$ alloy using a laboratory machine $[15,16]$.

Twelve cylindrical water-cooled targets were symmetrically located relative to the system axis and had a cathode potential. The material we sputtered was ten target cathodes made of a Co $-(18 \ldots 20 \%) \mathrm{Cr}-(5 \ldots 7 \%)$
$\mathrm{Al}-(0.3 \ldots 0.4 \%) \mathrm{Y}$ alloy (combinations varied). The electrical wiring circuit enabled us to measure the cut-off potential at target cathodes during the experiment. The substrate material we selected was different from the alloy components for easy X-ray fluorescence and X-ray spectroscopy microanalysis of coatings generated.

The sputtering parameters were as follows: $0.7 \mathrm{~Pa}$ working gas pressure, $2.2 \mathrm{~kW}$ discharge; the substrate holder had a positive constant potential $U_{\Pi}$. The latter value was experimentally adjusted to maximize the deposition rate. Prior to the deposition of the coating, substrates had been subjected to ion cleaning.

Multi-layer coatings were generated in the following order:

- first, we sputtered a heat-resistant CoCrAlY alloy. Cut-off potential was applied to aluminum and nickel targets.

- the second layer of the coating was generated by sputtering all the targets located in a vacuum chamber.

All the target cathodes had the same potential;

- the third layer was generated by sputtering the aluminum and nickel targets. Cut-off potential was applied to all the CoCrAlY cathodes;

- the outer layer was generated by sputtering an aluminum target. Nickel and alloy targets were under cut-off potential.

Given the physical characteristics of coating materials, the area of target cathodes, and how the current density changed thereon, we can pre-evaluate the generated coating composition.

On an isolated site, the thickness of single-component coating $(i=1)$ was as follows:

$$
\delta_{i}=K_{u i} \cdot K_{p i}\left(E_{i}\right) \cdot \frac{S_{M i}}{S_{\text {oбщ }}} \cdot \frac{A_{i} \cdot m_{a}}{\rho_{i} \cdot t} \cdot \frac{j_{k i}}{e} \cdot t_{o c . i}
$$

\footnotetext{
* Corresponding author: tokach@,bk.ru
} 
where $K_{u i}$ is the utilization factor of the $i$ th sputtered material; $S_{M i}$ is the surface area of the $i$ th sputtered component; $S_{\text {общ }}$ is the total area of the surface to which the coating is applied; $K_{p i}\left(E_{i}\right)$ is the sputtering coefficient of the $i$ th component that depends on the energy of plasma-generating gas ions bombarding the target cathode; $A_{i}$ is the atomic weight of the $i$ th component; $\rho_{i}$ is the density of the $i$ th sputtered material; $j_{k i}$ is the current density for the $i$ th target group; $t_{o c . i}$ is the time to sputter the $i$ th component.

As we identified the thickness of the coating, we concluded that this value could be approximated as the total of thicknesses of each component if those deposited layer-by-layer. X-ray fluorescence analysis showed that the ratio of component-specific thicknesses is numerically equal to the percentage of these components in the coating (within the experimental margin of error).

Therefore, when generating multi-component coating, its thickness can be viewed as the total of all componentspecific thicknesses:

$$
\delta_{\Sigma}=\sum_{i=1}^{N} \delta_{i}
$$

The mass flow density is inversely proportional to the square of the target-to-substrate distance [17]. As the substrate moves relative to the target cathodes, we can assume that distances from targets made of various materials to the substrate are roughly equal; the difference between such distances can be disregarded in further analysis.

The percentage of each component in the coating depended on the ratio of sputtered surfaces of target cathodes made of this component material to the total area of the receiving surface upon which the multi-component coating is deposited. The receiving surface in this case was the shell, in the plain of which the substrate moved. This fact is due to the radial discharge of plasma, a characteristic of the system under analysis [18].

Thus, by substituting (2) in (1) and factoring in the assumptions made, we obtain an expression to calculate the thickness of multi-component coatings:

$$
\delta_{\Sigma}=\sum_{i=1}^{N} K_{u i} \cdot \frac{S_{\text {мi }}}{S_{\text {оби }}} \cdot K_{p i}\left(E_{i}\right) \frac{A_{i} \cdot m_{a}}{\rho_{i} \cdot t} \cdot \frac{j_{k i}}{e} \cdot t_{\text {oci }}
$$

This method is for calculating the percentage of components in multi-component coatings; it can be used for pre-evaluation of the coating thickness. Based on our calculations, the projected film thickness was $59.5 \mu \mathrm{m}$.

\section{Studying the Multi-Layer Multi- Component Coatings}

Coatings were studied using a JSMT 300 scanning electron microscope with a Phoenix accessory for X-ray spectroscopy (XRS) by EDAX, USA. The chemical composition of the coating surface was determined by Xray fluorescence using an EX 6500 machine by BAIR, USA. XRF showed that the chemical elements sputtered were presented in the generated coating, see Table 1.
Table 1. XRF analysis results.

\begin{tabular}{|c|c|c|c|c|c|c|c|c|}
\hline Element & $\mathrm{Al}$ & $\mathrm{Cr}$ & $\mathrm{Fe}$ & $\mathrm{Co}$ & $\mathrm{Ni}$ & $\mathrm{Cu}$ & $\mathrm{Ti}$ & $\mathrm{Y}$ \\
\hline$\%$ & 70.5 & 2.8 & 10.9 & 1.2 & 8.0 & 0.8 & 5.9 & 0.06 \\
\hline
\end{tabular}

The generated coating was $59.00 \mu \mathrm{m}$ thick, see Figure 1.

There was no clear boundary between the layers, which might be due to the following. When sputtering a target cathode group at the rest of the targets under cut-off potential, a portion of the sputtered material is deposited. When cut-off potential is switched, first the material deposited on that target cathode group is sputtered, whereafter the targets themselves are sputtered as well. This generates a transient zone between the layers.

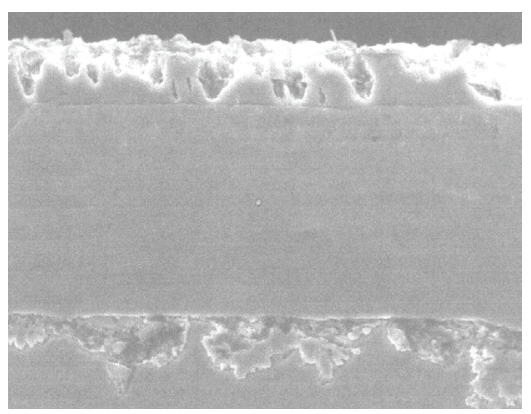

Fig. 1. Microsection of multi-layer multi-component coating.

The noted effect is a favorable factor for the formation of multilayer coatings. The system analyzed can generate multi-layer coatings with clear inter-layer boundaries. To do that, we have to experimentally find such cut-off potential that would prevent the deposition of sputtered materials on cut-off targets.

Based on X-ray spectroscopy microanalysis carried out in the spot-line scanning mode, we could see we generated a multi-layer coating with specified characteristics, see Figure 2, 3.

The percentage of chemical elements in the coating matched the order in which the main and the additional components had been modified, see Figure $2 b$.

In the initial sputtering of the CoCrAlY heat-resistant alloy, the percentage of components was preserved. The simultaneous sputtering of all target cathodes (heatresistant, aluminum, and nickel ones) having the same potential results in a change in the coating component concentration. Applying cut-off potential to target cathodes made of CoCrAlY considerably reduces the concentration of cobalt and chromium while increasing the percentage of aluminum and nickel. When generating the outer layer, nickel and alloy target cathodes were under cut-off potential, while the aluminum target was sputtered, which resulted in a considerable change in the component composition of this layer. Experimental data were in line with the projected results. The theoretical and the experimental data did not diverge by more than 8 $10 \%$, which proves that multi-layer coatings can be generated with thickness-adjustable percentage of chemical elements.

Figure 2c shows how the concentration of impurities in the coating was distributed. 
a)

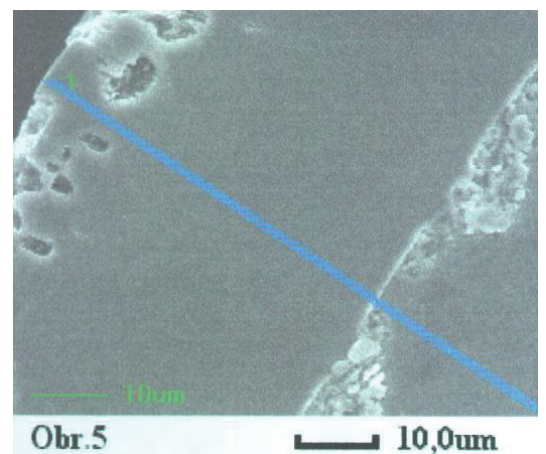

b)

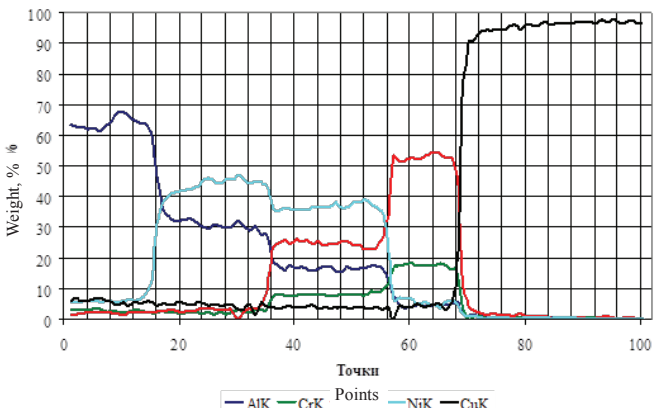

- AIK - CrK Points - NiK - CuK

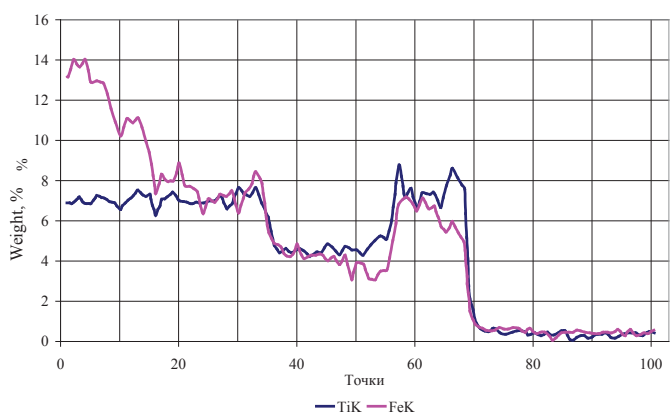

c)

Points

Fig. 2. Results of spot-line XRS scanning:

a) the electron probe scanning line;

b, c) the distribution of chemical components along the scanning line.

The distribution of chemical components in the coating as determined in the mapping mode (see Figure 3 ) shows that we obtained multi-layer multi-component coating were the components were uniformly distributed in the layer thickness.

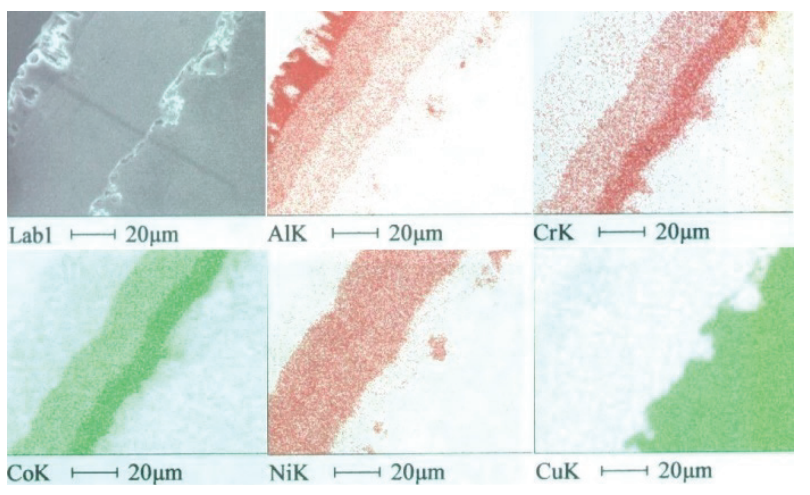

Fig. 3. Mapping-mode distribution of chemical elements

\section{Conclusions}

Studying the multi-component multi-layer coatings were generated revealed that:

- the coating contained the chemical elements sputtered;

- the thickness distribution of chemical elements was uniform, the boundary between the coating and the substrate was very clear, diffusion was virtually nonexistent;

- the coating was dense;

- the system analyzed can generate multi-layer components.

\section{References}

1. A. A. Achimov,

I. M. Tolmachyov, S. Yu. Udovichenko, Bulletin of Tyumen State University. 7, 105 (2014)

2. S. A. Muboyadzhan, S. A. Budinovsky, V. V. Terekhova, Metal Studies and Thermal Treatment of Metals, 1, 14 (2003)

3. A. N. Ramazanov, P. V. Beglikcheyev, Mechanical Engineering, Material Studies, and Thermal Treatment of Metals. 10, 108 (2008)

4. Yu. P. Tarasenko, Physics and Chemistry of Metal Processing. 4, 42 (2006)

5. A. G. Illarionov, A. A. Popov, Technological and Operating Properties of Titanium Alloys (Yekaterinburg, Ural University Publishing House, 2014)

6. V. M. Beresnyov, M. Yu. Kopeikina, S. A. Klimenko, Questions of Atomic Science and Technology. 1, 152 (2008)

7. V. Beletsky, V. Kireyev, S. Knyazev, D. Chelapkin, Modern Electronics. 2, 12 (2002)

8. Ye. V. Berlin, L. A. Seidman, Ion Plasma Processes in Thin-Film Technology (Tekhnosfera, 2006)

9. V. S. Mukhin, R. M. Kireyev, S. R. Schechtman, Bulletin of Ufa State Aviation Technical University. 12, 212 (2011)

10. Patent 2490369 Russian Federation, V. Ye. Beletsky, Apparatus for Application of Multi-Layer Components to Devices (2013)

11. Patent 2379378 Russian Federation, D. D. Slivakov, V. S. Mitin, A Method for Ion Plasma Application of Multi-Component Film Coatings and a Machine for Such Application (2010)

12. Patent 2210620 Russian Federation, M. I. Guseva, M. V. Atamanov, Yu. V. Martynenko, Yu. V. Moskovskin, V. S. Mitin, A. V. Mitin, S. A. Shiryayev, A Method for Ion Plasma Application of Multi-Component Film Coatings, a Mosaic Target for Such Application, and a Method for Making Such Targets (2003)

13. US Patent 6488824, Sputtering apparatus and process for high rate coatings (2002)

14. US Patent 20130056348 A1, Vacuum coating apparatus and method for depositing nanocomposite coatings (2013) 
15. V. V. Kolesnik, Yu. K. Rubanov, Yu. Ye. Tokach, Bulleting of V. G. Shukhov Bashkir State Technical University. 4, 110 (2017)

16. Utility Model Patent 159075 Russian Federation, V. P. Kolesnik, V. V. Kolesnik, Yu. K. Rubanov, Ye. I. Yevtushenko, Multi-Component Multi-Layer Coating Apparatus (2016)

17. B. S. Danilin, Use of Low-Temperature Plasma for Application of Thin Films (Moscow, Energoatomizdat, 1989)

18. V. V. Kolesnik, V. G. Padalka, I. V. Lunev, Aerospace Engineering and Technology (Aviatsionno- kosmicheskaya tekhnika i tekhnologiya). 12, 58 (1999) 